\title{
ICH guideline practice: application of novel RP-HPLC-DAD method for determination of olopatadine hydrochloride in pharmaceutical products
}

\author{
Pawan K Basniwal ${ }^{1,2^{*}}$ and Deepti Jain ${ }^{1}$
}

\begin{abstract}
Background: A novel reverse-phase high-performance liquid chromatography (RP-HPLC)-DAD method was developed, validated and applied to quantify olopatadine hydrochloride in pharmaceutical products.

Methods: The RP-HPLC analyses were carried out using a mixture of $0.1 \%$ formic acid and methanol (35:65) as a mobile phase on ZORBAX Eclipse Plus C18 $(250 \mathrm{~mm} \times 4.6 \mathrm{~mm}, 5 \mu \mathrm{m})$, with a flow rate of $1.0 \mathrm{~mL} / \mathrm{min}$ and UV detection at $300 \mathrm{~nm}$. The developed method was validated as per the International Conference on Harmonisation of Technical Requirements for Registration of Pharmaceutical for Human Use guidelines for linearity, range, accuracy, precision, robustness, limit of detection, limit of quantitation and specificity.

Results: The validated method was applied to quantify the drug content in raw material, tablets and eye drops which was found to be $99.36 \%$ to $101.02 \%, 98.99 \%$ to $100.56 \%$ and $99.09 \%$ to $100.91 \%$, respectively.

Conclusion: The method was found to be efficient, precise, accurate, specific and economic and useful for the routine analysis of olopatadine hydrochloride in pharmaceutical industries.
\end{abstract}

Keywords: Olopatadine hydrochloride; RP-HPLC; Pharmaceutical products

\section{Background}

Olopatadine (OLO) is a new histamine $\mathrm{H} 1$ receptorselective antagonist, chemically, 11-((Z)-3-(dimethyl-amino) propylidene)-6,11-dihydro-dibenz[b,e]oxepin-2-acetic acid (Ohshima et al. 1992) (Figure 1), used to treat allergic conjunctivitis (itching eyes) (Scoper et al. 2007; Kajita et al. 2002; McGill 2004; Takahashi et al. 2008; Ohishi et al. 1995). Very few assay methods were reported for the analysis of olopatadine, viz. radioimmunoassay method for humans (Tsunoo et al. 1995).

However, it had several problems, such as cross-reactivity of metabolites and low precision, and so it was considered that plasma concentrations of olopatadine measured by RIA needed to be confirmed by an alternative method.

\footnotetext{
* Correspondence: pawanbasniwal@gmail.com

'School of Pharmaceutical Sciences, Rajiv Gandhi Technological University, Bhopal, Madhya Pradesh 462 033, India

2LBS College of Pharmacy, Jaipur, Rajasthan 302 004, India
}

High-performance liquid chromatography (HPLC) with tandem mass spectrometry has been applied for the determination of a number of compounds in biological fluids (Zhu et al. 2011). Other assay methods for olopatadine and its metabolites in human plasma by HPLC with electrospray ionisation tandem mass spectrometry were reported (Fujimaki et al. 2006; Fujita et al. 1999). Varghese et al. (2011) have used $0.1 \%$ orthophosphoric acid (pH 4.5) with triethylamine/acetonitrile $(75: 25)$ for the determination of olopatadine hydrochloride. Triethylamine should be avoided as its addition to the mobile phase requires longer column equilibration times, which is not advisable for the routine use of the developed method. It occasionally introduces additional problems such as erratic baselines and poor peak shape and complicates the preparation of the mobile phase (Synder et al. 1997). A complicated buffer is a component of the mobile phase for the HPLC method, which includes monobasic potassium phosphate $(6.8 \mathrm{~g}), 1$-pentane sulphonic acid sodium 


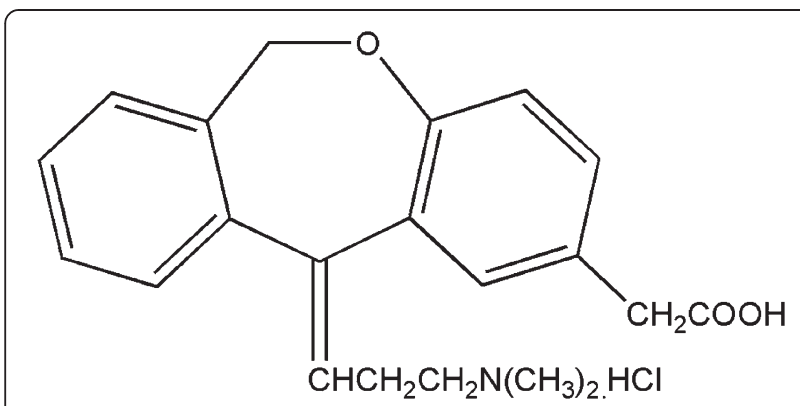

Figure 1 Structure of olopatadine hydrochloride.

salt monohydrate $(1.28 \mathrm{~g})$ and triethylamine $(3 \mathrm{~mL})$, and the $\mathrm{pH}$ is adjusted to 3.0 with orthophosphoric acid (Rele and Warkar 2011). Thus, both the above methods cannot be useful for routine analysis as tedious mobile phase composition and problem arise from triethylamine.

Hitherto, the objective of the present research work was to develop a simple, precise, accurate and fast reverse-phase high-performance liquid chromatography (RP-HPLC) assay method for the analysis of olopatadine hydrochloride in different pharmaceutical products including raw material, tablets and eye drops, and to compare the assay results by statistical analysis, which may be useful for routine analysis.

\section{Methods}

\section{Instrumentation and chromatograph}

The HPLC chromatograph used was Agilent Infinity 1260 series (Agilent Technologies, Inc., Santa Clara, CA, USA) equipped with 1260 binary pump VL (400 bar), 1260 manual injector (600 bar), Rheodyne 7725i seven-port sample injection valve with $20-\mu \mathrm{L}$ fixed loop, ZORBAX Eclipse Plus C18 (250 mm × $4.6 \mathrm{~mm}, 5 \mu \mathrm{m}), 1260$ DAD VL, 20-Hz detector, standard flow cell (10 mm, $13 \mu \mathrm{L}, 120 \mathrm{bar})$, OpenLab CDS EZChrom Ed. Workstation and syringe (50.0 $\mu \mathrm{L}, \mathrm{FN}, \mathrm{LC}$ tip). All weighing for analysis was performed on Shimadzu electronic analytical balance AX-200 (Kyoto, Japan). Water used for analysis was prepared by triple distillation assembly. All dilutions, mobile phase and other solutions that were used for the analysis were filtered through a 0.2- $\mu \mathrm{m}$ nylon filter (Ultipor ${ }^{\circledR} 66$ Nylon 6,6 membrane, Pall Sciences, Pall India Pvt. Ltd., Mumbai, India).

\section{Chemicals and reagent}

The working standard used was OLO which was supplied by Ranbaxy Laboratories Limited (Gurgaon, Harayana, India) as a gift sample. Formic acid and methanol were procured from Merck Specialties Private Limited (Mumbai, India). The mobile phase was prepared from the combination of formic acid (0.1\%) and methanol.

\section{Chromatography}

Accurately weighed $50 \mathrm{mg}$ of OLO was dissolved in 50\% aqueous methanol to prepare stock $\mathrm{I}(1,000 \mu \mathrm{g} / \mathrm{mL})$ in a
50-mL volumetric flask. Stock II $(100 \mu \mathrm{g} / \mathrm{mL})$ was prepared from stock I, which was used to prepare further dilutions containing 1, 5, 10, 15 and $20 \mu \mathrm{g} / \mathrm{mL}$. All dilutions were filtered through the $0.2-\mu \mathrm{m}$ nylon filter (Ultipor ${ }^{\circ} \mathrm{N} 66$ Nylon 6,6 membrane, Pall Sciences) and chromatographed by a set of conditions on Agilent Infinity 1260 series. The mixture of $0.1 \%$ formic acid and methanol (35:65) was used as the mobile phase for the elution of the drug on Zorbax Eclipse Plus C18 column $(250 \mathrm{~mm} \times 4.6 \mathrm{~mm}, 5 \mu \mathrm{m})$ at $1.0 \mathrm{~mL} / \mathrm{min}$ flow rate. OLO was successfully eluted at $3.77 \mathrm{~min}$ with a run time of $7 \mathrm{~min}$, and detection was performed using a photodiode array detector (PDA) at $300 \mathrm{~nm}$.

\section{Method validation}

According to the International Conference on Harmonisation of Technical Requirements for Registration of Pharmaceutical for Human Use (ICH) guidelines (ICH 2000a, b), the developed method was validated to assure the reliability of the results of analysis for the different parameters, viz. linearity, range, accuracy, precision, robustness, limit of quantization (LOQ), limit of detection (LOD) and specificity. Linearity was determined by serial dilutions ( 1 to $20 \mu \mathrm{g} / \mathrm{mL}$ ) of the OLO in $50 \%$ aqueous methanol in triplicate. The range of OLO was validated between 5 and $15 \mu \mathrm{g} / \mathrm{mL}$ with triplicates of dilutions. The recovery method was used to determine the accuracy of the developed method by spiking the standard solution to the pre-analysed samples $(5,10$ and $15 \mu \mathrm{g} / \mathrm{mL})$, which was repeated six times. Repeatability and intermediate precision were studied to assure the precision of the method. Six replicates of the standard dilution $(5 \mu \mathrm{g} / \mathrm{mL})$ were chromatographed subsequently to assure repeatability, which were further chromatographed after $5 \mathrm{~h}$ to assure the stability of the drug in the solvent system. The standard dilutions were analysed by different analysts in subsequent days to study intermediate precision in the linearity range. A change in temperature $\left(20^{\circ} \mathrm{C}, 25^{\circ} \mathrm{C}\right.$ and $\left.30^{\circ} \mathrm{C}\right)$ and acidic content of the aqueous part of the mobile phase ( $5 \%$ change in $0.1 \%$ aqueous formic acid) was observed. Different serial dilutions of OLO (0.1 to $1,000 \mathrm{ng} / \mathrm{mL}$ ) were chromatographed to calculate the signal-to-noise ratio to determine LOD and LOQ. Alkaline-degraded OLO samples were chromatographed to ascertain the specificity of the developed method for OLO.

\section{Analysis of pharmaceutical products Raw material}

As per the 'Chromatography' subsection, the samples of raw material have been prepared and analysed in the set of condition of analysis, which was repeated in six batches. The response to chromatographic analysis was used to calculate the concentration with the help of a regression equation. 


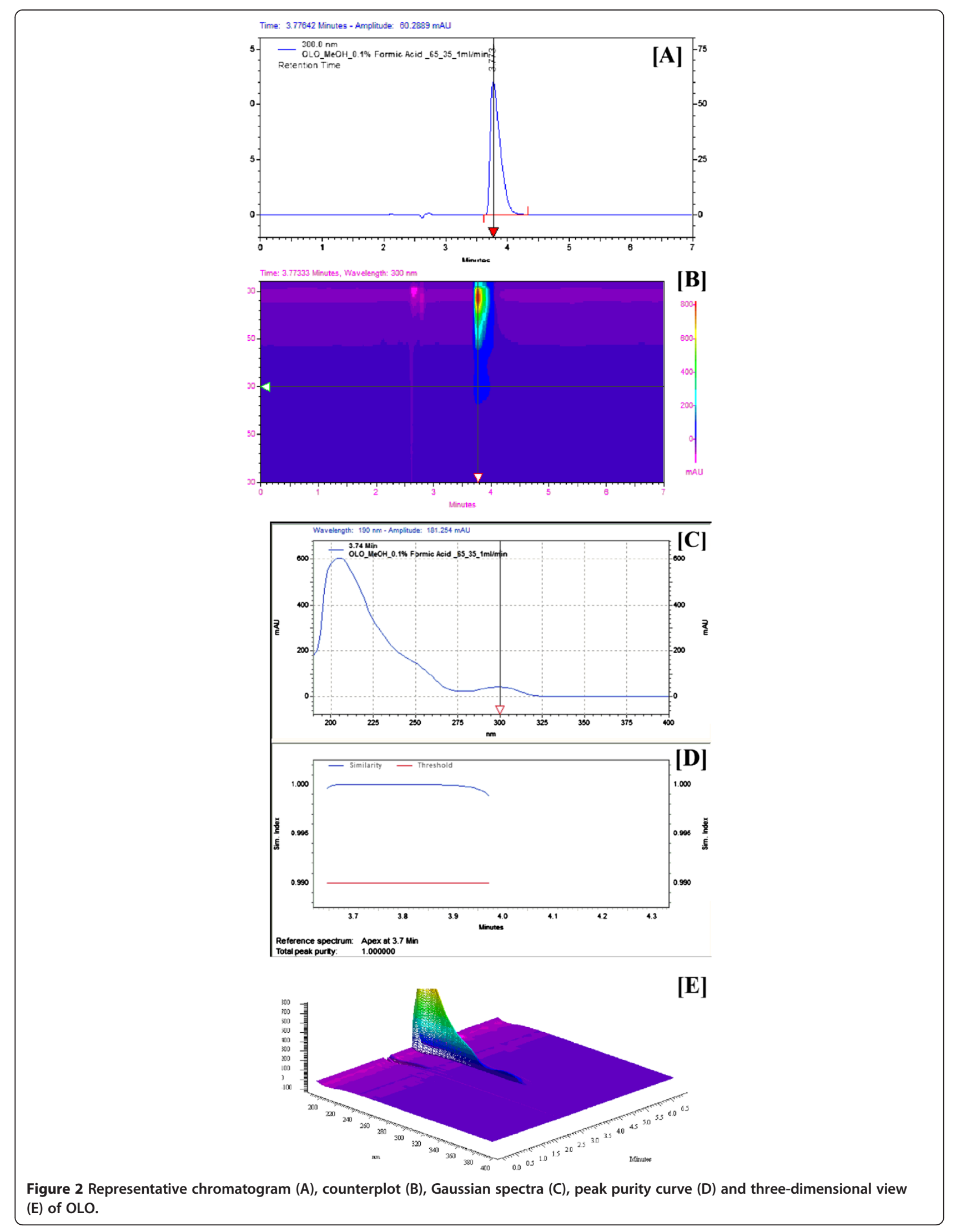




\section{Tablets}

Powdered tablets were weighed equivalently to $50 \mathrm{mg}$ of OLO and sonicated to dissolve the drug content in methanol to extract the complete drug content from the tablet powder. The sonicated solution was filtered through Whatman filter no. 41 to remove the un-dissolved excipients of the tablet dosage form, and different serial dilutions were prepared by subsequent dilution with 50\% aqueous methanol. All dilutions were filtered through the $0.2 \mu \mathrm{m}$ nylon filter and chromatographed. The drug content was determined from the regression equation.

\section{Eye drops}

An accurately measured volume of ophthalmic solution (Olodin, FDC Limited, Aurangabad, India), equivalent to about $10 \mathrm{mg}$ of OLO, was transferred to a $100 \mathrm{~mL}$ 163 volumetric flask and diluted with diluent to the volume. The solution was mixed and sonicated for $10 \mathrm{~min}$. An appropriate dilution was prepared from the stock solution and filtered (stock P, $100 \mu \mathrm{g} / \mathrm{mL}$ ). Aliquots of stock P were diluted to get sample concentrations $(5,10$ and $15 \mu \mathrm{g} / \mathrm{mL})$ in the range of linearity for the developed method and filtered through the $0.2 \mu \mathrm{m}$ nylon filter. All these dilutions were chromatographed, and the area under the curve (AUC) of the peak of OLO was placed in the regression equation to get the concentration of the samples.

\section{Results and discussion}

\section{Optimization of chromatography}

The aim of this research work was to develop a novel RP-HPLC method for the determination of OLO in different matrices by eliminating the triethylamine component in the mobile phase, which improves the peak shape associated with other number of troubles to the column. Keeping the view of the results with triethylamine use in the mobile phase, the physical properties of OLO were used to improve the chromatographic parameters. On the basis of the solubility of OLO, different combinations of the mobile phase were tried to elute on C18 column. Broadening and splitting of the peak have been seen with the mixture of methanol and water (50:50) and the mixture of acetonitrile and water (50:50). The $\mathrm{p} K_{\mathrm{a}}$ value (4.29) has been taken into account to design the mobile phase composition as OLO has a carboxylic group. So $0.1 \%$ formic acid was added to the aqueous phase of the mixture of acetonitrile and water (50:50), but the same broadening of peak with a little bit splitting of peak was observed. Tailing was found with the mixture of methanol and water (50:50) along with the acidic content of the aqueous phase which was improved by increasing the concentration of methanol content in the mobile phase. A very sharp peak shape was found with $70 \%$ content of methanol in the mobile phase, but it was merging with the diluent peak when a higher value was present at $60 \%$. Thus, chromatographic conditions were concluded to be better than the reported methods.

The mixture of $0.1 \%$ formic acid and methanol (35:65) was selected to elute OLO on C18 column with $1 \mathrm{~mL} / \mathrm{min}$ flow rate, where it was eluted at $3.77 \mathrm{~min}$ with acceptable peak shape and tailing factor (Figure 2A). A counterplot of the chromatogram was able to show the exact position of the elution point where time and wavelength cross each other (Figure 2B). The detection wavelength was $300 \mathrm{~nm}$, which was the $\lambda$ max of OLO (Figure $2 \mathrm{C}$ ).

The peak purity of OLO in the chromatogram was 1 unit which was supported by the peak purity curve (Figure 2D). A three-dimensional view of the chromatogram was the proof for no interference to the peak of OLO (Figure 2E).

\section{System suitability parameters}

Acceptable system suitability results for a chromatographic run establish that the method is performing adequately and can be used to generate reportable data. It includes the number of theoretical plates, tailing factor, retention time and peak purity of the analyte. The number of theoretical plates for the C18 column was 8,578 $(n=6)$ with an acceptable relative standard deviation (\%RSD) value of 1.09, which indicates that the column performance was excellent. OLO should have tailing in the chromatogram on C18 column if the mobile phase is without diethylamine or triethylamine as it has a tertiary amino functional group. The formic acid content of the aqueous phase of the mobile phase was solved to have an acceptable limit of tailing factor (1.31) with a \%RSD of 0.49 . The retention time for OLO was $3.77 \mathrm{~min}$ in the 7 min run time of analysis. The peak purity of the OLO was always 1 at $3.77 \mathrm{~min}$ (Table 1 ).

\section{Method validation}

A linear relationship was found between the OLO concentrations and the response to chromatographic analysis which was demonstrated by high regression coefficients $\left(r^{2}=0.999\right)$ for the concentration of 1 to $20 \mu \mathrm{g} / \mathrm{mL}$ and the mean regression equation was found as $\mathrm{AUC}=$ $79,991 X-64,340$. The working range for the drug was selected to be 5 to $15 \mu \mathrm{g} / \mathrm{mL}$. Accuracy was investigated by the recovery of standard addition to pre-analysed samples which was near 100\% with acceptable \%RSD. Intra-day variation (repeatability) and intermediate

Table 1 System suitability parameters for OLO in $\mathbf{0 . 1 \%}$ formic acid and methanol (35:65) on C18 column

\begin{tabular}{lccc}
\hline Parameters & Value $(\boldsymbol{n}=\mathbf{6})$ & SD & \%RSD \\
\hline Number of theoretical plates & 8,578 & 42.63 & 1.09 \\
\hline Tailing factor & 1.31 & 0.94 & 0.49 \\
\hline RT (min) & 3.77 & 0.046 & 0.021 \\
\hline Peak purity & 1 & 0 & 0 \\
\hline
\end{tabular}

$S D$ standard deviation, $R S D$ relative standard deviation, $R T$ retention time. 
Table 2 Validation parameters for olopatadine hydrochloride

\begin{tabular}{ll}
\hline Parameters & Values $^{\text {a }} \pm$ SD, \pm \%RSD \\
\hline Linearity & 1 to $20 \mu \mathrm{g} / \mathrm{mL}$ \\
\hline Regression equation & AUC $=79,991 X-64,340$ \\
\hline Correlation coefficient & $r^{2}=0.999 \pm 0.001, \pm 0.100$ \\
\hline Range & 5 to $15 \mu \mathrm{g} / \mathrm{mL} \pm 1.08, \pm 0.51$ \\
\hline Accuracy & $100.11 \pm 1.065, \pm 0.784$ \\
\hline Precision & \\
\hline Repeatability & $99.94 \pm 0.742, \pm 0.482$ \\
\hline Intermediate precision & \\
\hline Inter-day & $100.08 \pm 0.825, \pm 0.091$ \\
\hline Analyst to analyst & $99.89 \pm 0.929, \pm 0.027$ \\
\hline Robustness & \\
\hline Temperature $\left(20^{\circ} \mathrm{C}, 25^{\circ} \mathrm{C}\right.$ and $\left.30^{\circ} \mathrm{C}\right)$ & $99.91 \pm 0.816, \pm 0.089$ \\
\hline Formic acid concentration $( \pm 5 \%)$ & $100.06 \pm 0.794, \pm 0.296$ \\
\hline LOQ & $5 \mathrm{ng} / \mathrm{mL} \pm 1.098, \pm 0.566$ \\
\hline LOD & $0.5 \mathrm{ng} / \mathrm{mL} \pm 1.691, \pm 0.295$ \\
\hline Specificity & $\begin{array}{l}\text { Ascertained by analysing standard } \\
\text { drug and degraded sample of } \\
\text { equivalent concentration }\end{array}$ \\
\hline
\end{tabular}

${ }^{a}$ Mean of six replicates. $S D$ standard deviation, $R S D$ relative standard deviation, $A U C$ area under the curve, $L O Q$ limit of quantification, $L O D$ limit of detection.

precision (days and analyst variation) were evaluated by analysing quality control samples containing low, medium and high concentrations of OLO.

For intra-day variation, sets of the six replicates of the three concentrations were analysed on the same day; for intermediate precision, the six replicates were analysed on three different days by three different analysts. All results of precision were between $99.89 \%$ and $100.08 \%$ within the acceptable limits of \%RSD values, and there was no significant difference in the results of the analysis when drug samples were analysed after $5 \mathrm{~h}$. The developed method is robust when it was unaffected by small changes in operating conditions of the analysis. The experimental conditions were deliberately altered at three different levels, and chromatographic response was evaluated.

Changes in temperature of analysis time and formic acid percent of the aqueous part of the mobile phase were studied as robustness factors, and one factor at a time was changed to study the effect on the result of the method. The results of robustness vary between $99.91 \%$ and $100.06 \%$ with less than 1 unit of the \%RSD value (Table 2). The LOD and LOQ were determined by considering the signal-to-noise ratio of 3 and 10, respectively. The developed method was highly sensitive to OLO as LOD and LOQ values were found to be 0.5 and $5 \mathrm{ng} / \mathrm{mL}$, respectively. The method was specific to the drug as PDA analyses proved that the peak purity for the drug peak in a mixture of stressed samples was 1 unit. The purity threshold curve hereby indicated that the drug peak was free from any co-eluting peak (Figure 2E).

\section{Analysis of products}

The validated chromatographic method was applied to determine OLO in raw material, tablets and eye drops, where six batches were prepared for each quality control sample $(5,10$, and $15 \mu \mathrm{g} / \mathrm{mL})$ for all pharmaceutical products.

OLO was determined in raw material within the range of $99.36 \%$ to $101.02 \%$ with a standard deviation of 0.556 . In the tablet dosage form, the drug content was found to be within the range of $98.99 \%$ to $100.56 \%$ with a standard deviation of 0.404 . In a similar fashion, the OLO content in the eye drop was estimated to be in the range of $99.09 \%$ to $100.91 \%$ with a standard deviation of 0.498 (Table 3 ). Thus, all the pharmaceutical products have been analysed within the acceptable limits.

\section{Conclusion}

Hence, the simple, fast, precise, accurate and novel reverse-phase liquid chromatographic method was developed and validated according to $\mathrm{ICH}$ guidelines. The

Table 3 Analysis of olopatadine hydrochloride in pharmaceutical products

\begin{tabular}{|c|c|c|c|c|c|c|c|c|c|}
\hline \multirow{3}{*}{ Batch } & \multicolumn{9}{|c|}{ Concentration of quality control samples (\%) } \\
\hline & \multicolumn{3}{|c|}{ Raw material ( $\mu \mathrm{g} / \mathrm{mL})$} & \multicolumn{3}{|c|}{ Tablet $(\mu \mathrm{g} / \mathrm{mL})$} & \multicolumn{3}{|c|}{ Eye drop $(\mu \mathrm{g} / \mathrm{mL})$} \\
\hline & 5 & 10 & 15 & 5 & 10 & 15 & 5 & 10 & 15 \\
\hline A & 100.23 & 100.92 & 99.83 & 99.93 & 99.99 & 100.19 & 100.83 & 99.48 & 100.03 \\
\hline B & 101.02 & 99.28 & 100.12 & 98.99 & 99.63 & 99.92 & 100.41 & 100.69 & 100.28 \\
\hline$C$ & 99.36 & 100.04 & 99.94 & 100.29 & 100.59 & 100.46 & 99.98 & 100.83 & 99.56 \\
\hline $\mathrm{D}$ & 98.94 & 100.91 & 100.46 & 100.06 & 100.48 & 100.56 & 99.74 & 99.93 & 99.09 \\
\hline $\bar{E}$ & 100.32 & 99.76 & 99.83 & 99.89 & 99.67 & 99.89 & 100.46 & 100.91 & 100.06 \\
\hline$F$ & 100.19 & 99.89 & 100.11 & 100.56 & 100.16 & 100.15 & 100.29 & 100.02 & 100.04 \\
\hline Mean & 100.01 & 100.13 & 100.05 & 99.95 & 100.09 & 100.20 & 100.29 & 100.31 & 99.84 \\
\hline SD & & 0.556 & & & 0.404 & & & 0.498 & \\
\hline
\end{tabular}


validated method was successfully applied to determine the OLO content in pharmaceutical products including raw material, tablets and eye drops with acceptable limits. As previous reported methods may not be applied for routine analysis due to the use of the triethylamine component in the mobile phase, this novel RP-HPLC method might be applied for assays, dissolution studies, bio-equivalence studies as well as routine analysis of OLO in pharmaceutical industries.

\section{Competing interests}

Both authors declare that they have no competing interests.

\section{Authors' contributions}

Both authors equally contributed in experimental design, framing, writing, proofing and approval of the manuscript. Experimental work was done by PKB.

\section{Acknowledgements}

One of the authors, Pawan Kumar Basniwal, is earnestly indebted to the Science and Engineering Research Board (SERB), DST, New Delhi, for the financial support for this research work under Fast Track Scheme for Young Scientists. The authors are highly thankful to the Head of the School of Pharmaceutical Sciences, RGPV, Bhopal, and the Principal of the LBS College of Pharmacy, Jaipur, for providing the experimental facilities for this research work.

Received: 16 July 2013 Accepted: 22 August 2013 Published: 03 Sep 2013

\section{References}

Fujimaki K, Lee XP, Kumazawa T, Sato J, Sato K (2006) Determination of some anti-allergic drugs in human plasma by direct-injection high-performance liquid chromatography-tandem mass spectrometry. Forensic Toxicol 24:8-16

Fujita K, Magara H, Kobayashi H (1999) Determination of olopatadine, a new anti-allergic agent, and its metabolites in human plasma by high-performance liquid chromatography with electrospray ionization tandem mass spectrometry. J Chromatogr B 731:345-352, S0378-4347(99)00236-4

ICH (2000a) Q2A: text on validation of analytical procedures. International Conference on Harmonisation of Technical Requirements for Registration of Pharmaceutical for Human Use, Geneva

ICH (2000b) Q2B: validation of analytical procedure: methodology. International Conference on Harmonisation of Technical Requirements for Registration of Pharmaceutical for Human Use, Geneva

Kajita J, Inano K, Fuse E, Kuwabara T, Kobayashi H (2002) Effects of olopatadine, a new anti-allergic agent, on human liver microsomal cytochrome p450 activities. Drug Metabo Disposit 30:1504-1511

McGill I (2004) A review of the use of olopatadine in allergic conjunctivitis. Int Ophthalmology 25(3):171-179

Ohishi T, Magara H, Yasuzawa T, Kabayashi H, Yamaguchi K, Kobayashi S (1995) Disposition of KW-4679 (4): metabolism of KW-4679 in rats and dogs. Xenobiol Metab Dispos 10:689-706

Ohshima E, Sato H, Obase H, Uchimura T, Kuwabara T, Kobayashi S (1992) Synthesis of a dibenz [b, e]oxepin-bovine serum albumin conjugate for radioimmunoassay of KW-4679 ((Z)-11-[3-(dimethylamino)propylidene]-6, 11-dihydrodibenz[b, e]oxepin-2-acetic acid hydrochloride). Chem Pharm Bull 40:2552-2554

Rele RV, Warkar CB (2011) Application of high performance liquid chromatographic technique for olopatadine hydrochloride and its impurity in ophthalmic solution. Int J Chem Sci 9(2):601-614

Scoper SV, Berdy GJ, Lichtenstein SJ, Rubin JM, Bloomenstein M, Prouty RE, Vogelson CT, Edwards MR, Waycaster C, Pasquine T, Gross RD, Robertson SM (2007) Perception and quality of life associated with the use of olopatadine $0.2 \%$ (Pataday $^{\mathrm{TM}}$ ) in patients with active allergic conjunctivitis. Adv Ther 24:1221-1232

Synder LR, Kirkland JJ, Glajch JL (1997) Practical HPLC method development, 2nd edn. Wiley, New York, p 430
Takahashi H, Zhang Y, Morita E (2008) Evaluation of the anti-histamine effects of olopatadine, cetirizine and fexofenadine during a $24 \mathrm{~h}$ period: a double-blind, randomized, crossover, placebo-controlled comparison in skin responses induced by histamine iontophoresis. Arch Dermatol Res 300:291-295

Tsunoo M, Momomura S, Masuo M, lizuka H (1995) Phase I clinical study on KW-4679, an anti-allergic drug: safety and pharmacokinetics in the single and repeated administration study to healthy subjects. Kiso To Rinsho 29:4129-4147

Varghese SJ, Kumar AM, Ravi TK (2011) Stability-indicating high-performance column liquid chromatography and high-performance thin-layer chromatography methods for the determination of olopatadine hydrochloride in tablet dosage form. J AOAC Int 94(6):1815-1820

Zhu P, Wen Y, Fan XP, Zhou ZL, Fan RX, Chen JM, Huang KL, Zhu XL, Chen YF, Zhuang J (2011) A rapid and sensitive liquid chromatography-tandem mass spectrometry method for determination of olopatadine concentration in human plasma. J Ana Toxicol 35:113-118

10.1186/2093-3371-4-12

Cite this article as: Basniwal and Jain: ICH guideline practice: application of novel RP-HPLC-DAD method for determination of olopatadine hydrochloride in pharmaceutical products. Journal of Analytical Science and Technology 2013, 4:12

\section{Submit your manuscript to a SpringerOpen ${ }^{\odot}$ journal and benefit from:}

- Convenient online submission

Rigorous peer review

- Immediate publication on acceptance

- Open access: articles freely available online

- High visibility within the field

- Retaining the copyright to your article

Submit your next manuscript at springeropen.com 